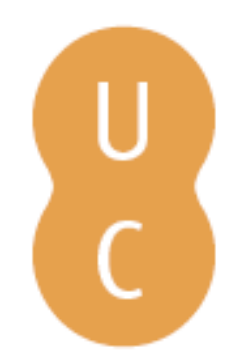

\title{
nombalina
}

\section{El mito de Fedra en la literatura árabe clásica de origen oriental}

Autor(es): Moral, Celia del

Publicado por: Centro de Estudos Clássicos e Humanísticos da Universidade de

URL

persistente: URI:http://hdl.handle.net/10316.2/30258

DOI: $\quad$ DOI:http://dx.doi.org/10.14195/978-989-721-038-9_37

Accessed : $\quad$ 26-Apr-2023 02:19:22

A navegação consulta e descarregamento dos títulos inseridos nas Bibliotecas Digitais UC Digitalis, UC Pombalina e UC Impactum, pressupõem a aceitação plena e sem reservas dos Termos e Condições de Uso destas Bibliotecas Digitais, disponíveis em https://digitalis.uc.pt/pt-pt/termos.

Conforme exposto nos referidos Termos e Condições de Uso, o descarregamento de títulos de acesso restrito requer uma licença válida de autorização devendo o utilizador aceder ao(s) documento(s) a partir de um endereço de IP da instituição detentora da supramencionada licença.

Ao utilizador é apenas permitido o descarregamento para uso pessoal, pelo que o emprego do(s) título(s) descarregado(s) para outro fim, designadamente comercial, carece de autorização do respetivo autor ou editor da obra.

Na medida em que todas as obras da UC Digitalis se encontram protegidas pelo Código do Direito de Autor e Direitos Conexos e demais legislação aplicável, toda a cópia, parcial ou total, deste documento, nos casos em que é legalmente admitida, deverá conter ou fazer-se acompanhar por este aviso.

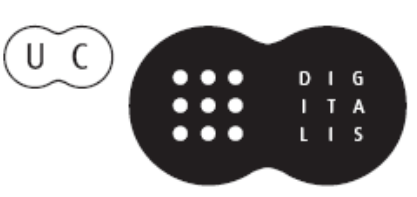




\section{De ayer a hoy}

\section{Influencias clásicas en la literatura}

\section{Aurora López, Andrés Pociña, Maria de Fátima Silva (coords.)}




\title{
El mito de Fedra en la literatura Árabe clásica de ORIGEN ORIENTAL
}

\author{
Celia del Moral \\ Universidad de Granada
}

\begin{abstract}
En esta comunicación analizaremos la versión árabe del mito de Fedra y su huella en la literatura árabe a través de obras como el Sendebar y Las Mil y una noches, comparándola con sus antecedentes griego y latino. Analizaremos las características de los personajes, los escenarios en que se mueven y la intención moralizante de estas obras, enmarcado en la corriente misógina que desde la India y a través de la literatura árabe se extiende por Europa a lo largo de la Edad Media.
\end{abstract}

Pocas cosas se pueden añadir ya al mito de Fedra e Hipólito y de su influencia en la Literatura universal que no hayan sido dichas en el magnífico libro editado por Aurora López y Andrés Pociña: Fedras de ayer y de hoy, fruto de un Simposio internacional celebrado en Granada en 2005.

En este libro encontramos (como bien saben muchos de los presentes) la figura de Fedra y de los otros personajes que forman parte de la tragedia analizados desde todos o casi todos los puntos de vista, así como las numerosas versiones que el mito ha dado lugar desde la antigüedad clásica hasta nuestros días.

Sin embargo, los que nos dedicamos al estudio de la Literatura árabe clásica, echamos de menos una versión del mito en esta literatura en una obra de origen oriental, como es la India o la antigua Persia, y que a través de las traducciones realizadas durante el califato abbasí, entre los siglos VIII al X, fue conocida y adaptada a la cultura árabe-islámica, formando parte de Las mil y una noches, la obra más emblemática de la literatura árabe, y, viajando simultáneamente a Occidente, es decir a al-Andalus, de donde fueron de nuevo traducidas al castellano a través de la Escuela de Traductores de Toledo y difundida por toda Europa. Me refiero al Sendebar, Syntipas o Sindibad, conocida en Occidente a través de su traducción con el título de Libro de los engaños e los asayamientos de las mugeres ${ }^{1}$, un libro de clara intención misógina, destinado a demostrar las maldades y mentiras inherentes al sexo femenino, cuya historia marco o hilo conductor recrea el mito de Fedra en su versión oriental.

Como se ha dicho ya repetidas veces, estamos ante una situación de carácter universal que nace de la propia naturaleza humana y que puede darse

${ }^{1}$ Ed. de Ma Jesús Lacarra. Madrid: Cátedra, 1995; véase también Versiones castellanas del Sendebar. Ed. y prólogo de Ángel González Palencia, Madrid - Granada, 1946. 
en cualquier tiempo y cultura: el hombre maduro, casado de antemano con otra $\mathrm{u}$ otras mujeres, que tiene un hijo único durante mucho tiempo deseado, que en su madurez o vejez se enamora y casa de nuevo con una muchacha joven, para que le de nuevos hijos y le haga vivir la ilusión de una segunda juventud. Al convivir en una misma casa o palacio el hijo joven o adolescente con la nueva esposa de su padre, de la misma o parecida edad, surge entre ellos el amor o la pasión, cuya iniciativa puede venir de parte de uno o de otro, y de ahí nace la tragedia al chocar el amor del hijo o de la joven esposa con los derechos legítimos del padre y con la sombra del incesto planeando sobre el triangulo amoroso. El final es variado, según las versiones: en unos casos termina con la muerte de ambos a manos del padre, o una condena, o el destierro o el perdón, según la cultura y la religión del momento.

E1 Sendebar, Syntipas o Sindbādal-Hakim una conocida obra perteneciente al género narrativo, como el Kalila y Dimna o Las mil y una noches, con una estructura muy similar a estas dos: la técnica de cuentos de cajón e historiamarco, cuyo origen es incierto y ha dado lugar a todo tipo de teorías, puesto que no se conoce el original. La opinión más extendida es que tiene su origen en la India, al igual que las otras dos obras citadas, en una fecha incierta, y que de allí pasó a Persia y a través del pahlevi fue traducido a la literatura árabe, donde es mencionada por algunos autores en el siglo X. De Oriente viajó a al-Andalus, siendo por último traducido del árabe al castellano en el siglo XII por encargo del infante D. Fadrique, hermano de Alfonso X el Sabio.

Otras hipótesis hablan de un origen persa, del s. VI, quizás de influencia helenística, o incluso de un origen hebreo (Sindabar), por su parecido a algunos pasajes bíblicos como la historia de José y la mujer de Putifar. Sea como sea, el original se ha perdido, no hay noticias de su autor ni de la fecha en que fue compuesto, pero lo cierto es que a partir de su traducción al castellano en el siglo XII fue conocido e imitado en toda Europa y tuvo una gran influencia en la narrativa occidental. Entre otras versiones encontramos la Historia de los Siete Sabios de Roma o la Historia lastimosa del Principe Erasto².

En Las mil y una noches aparece recogido entre las noches 578 y 606, con el título de "Historia que trata de las astucias de las mujeres y de su gran picardía", título muy semejante al de la traducción castellana, y dado que esta obra es una recopilación posterior de historias y cuentos de muy diversa procedencia, añadidos a un manuscrito primitivo -probablemente de la misma procedencia que el Sendebar-, es muy posible que el original utilizado para la traducción al

\footnotetext{
${ }^{2}$ Versiones castellanas del Sendebar, op. cit.

${ }^{3}$ Las Mil y Una Noches. Traducción, introducción y notas de Juan Vernet. Barcelona: Planeta, 2000, 2 vols, II, 297-369.
} 
castellano y la historia insertada en Las mil y una noches sea la misma, si bien los traductores al castellano la adaptaron a la sociedad medieval cristiana, mientras que los traductores al árabe la islamizaron.

La conexión con el mito de Fedra ya fue señalado por Vicente Cristobal en su artículo: "Recreaciones novelescas del mito de Fedra y relatos afines" ${ }^{4}$. Como señala este estudioso del tema, aparece con cierta frecuencia en la literatura india, citando a Frenzel que lo hace derivar del Kumala indio, puede tratarse de una influencia del mito griego o de una coincidencia temática puesto que como ya se ha dicho, es un tema universal.

En cuanto a los personajes, coinciden en líneas generales con los de la tragedia greco-latina. Si en Eurípides y Seneca hay cuatro personajes principales: Fedra, Hipólito, Teseo y la nodriza, junto con otros secundarios como el mensajero y el coro, en el Sendebar encontramos: el rey Alcos de Judea, que sería el equivalente a Teseo, la reina madre (sin nombre), una de las 90 mujeres del rey, el príncipe (sin nombre) que sería el equivalente a Hipólito, la favorita, que representa a Fedra y los 7 sabios (de entre los 900 del reino), en especial uno de ellos que ocupa el lugar de preceptor del príncipe, de nombre Çendubete, deformación del nombre original de Sendebar, Sindibād o Syntipas, este personaje podría ser el equivalente a la nodriza, pero que en vez de ayudar o aconsejar a la madrastra, aconseja y vela por el Príncipe, mientras que la madrastra no tiene quien la defienda y debe hacerlo sola.

En Las mil y una noches los personajes principales son: el rey (esta vez sin nombre, su esposa (que era su prima), el príncipe, la concubina (favorita del rey) y el sabio, de nombre Sindibād, original del que derivan los otros nombres como Sendebar, Syntipas o Çendubete. Aquí la historia marco está mucho más esquematizada que en los anteriores.

En la versión de Los siete sabios de Roma, el personaje de Teseo está representado por el emperador Ponciano, la emperatriz es hija de un rey, el príncipe se llama Diocleciano, la madrastra es hija del rey de Polonia y de nuevo aparecen los siete sabios (aquí, de Roma) que dan nombre a la obra. Todos estos sabios que aconsejan y cuentan historias a modo de ejemplos para convencer al rey de las maldades de las mujeres, podrían ser el equivalente al papel del coro en la Fedra de Seneca o el Hipólito de Eurípides.

La localización de la historia varía en cada obra, como es natural, dependiendo de la cultura y de la época, aunque en unos casos esté más definido que en otras, lo cual nos demuestra la universalidad del mito. Si en la tragedia clásica el mito se localiza en Atenas, en donde reinaba Teseo, en el Sendebar

\footnotetext{
${ }^{4}$ Cuadernos de Filología Clásica, 24 (1990), 111-125.
} 
(según la versión castellana) Alcos es el rey de Judea. En Las mil y una noches no indica de donde era el rey no donde se localiza la acción sino que como en muchos de los cuentos de esta obra, la acción queda indefinida en el espacio y el tiempo, lo que le da una mayor universalidad.

Dice Sharazad:

"Me han contado que en lo más antiguo del tiempo y en lo más remoto de las edades hubo un rey que tenía muchos soldados y auxiliares y era generoso y rico, pero había llegado a cierta edad y no tenía ningún hijo varón. Se dirigió a Dios por mediación del Profeta y le pidió que le diera un hijo varón que heredase el reino después de su muerte y que fuera la niña de sus ojos. Acto seguido se dirigió a la habitación en que vivía, mando llamar a su prima, que era su esposa, y se unió a ella. La esposa, con la ayuda de Dios, quedo embarazada y así estuvo hasta el momento del parto. Entonces dio a luz un hijo varón, cuyo rostro era como la luna en su decimocuarta noche....".

En las versiones derivadas del Sendebar la acción se sitúa en Roma (Historia de los siete sabios de Roma) o en Padua (Historia lastimosa del Principe Erasto) ${ }^{6}$.

En cuanto a la intención de la obra, si en la tragedia griega y latina la intención de la obra es la propia tragedia y la imposibilidad de luchar contra el destino, en el Sendebar y en Las mil y una noches la intención es didáctica, moralizante y misógina, la finalidad es educar a los jóvenes de clase alta en todos los aspectos de la vida que deberían conocer. Se trata del género literario conocido como adab, que abarca todas las disciplinas del saber y que no tiene un equivalente exacto en la literatura occidental.

Entre los muchos conocimientos que se suponía debían de conocer los jóvenes cultos, está el distinguir la mujer buena y honesta de la mala y adultera y para ello se componen una serie de libros de adab donde se trata de demostrar la maldad y la astucia de las mujeres a fin de que el joven no cayera en sus redes y supiera elegir una buena esposa (aunque la realidad es que la esposa generalmente la elegía su familia, ya que los matrimonios en las clase alta, como en otras muchas culturas, era un convenio entre familias que respondía más a cuestiones económicas o alianzas de poder que a los sentimientos de los contrayentes. De todas formas, parece ser que la virtud, honradez o maldad de las mujeres era un tema que entraba dentro de la formación de los jóvenes y por ello encontramos en la literatura árabe abundancia de obras o de capítulos (dentro de obras misceláneas) sobre este tema, y en este caso se acude a los cuentos o apólogos para ilustrar el mensaje que se quiere trasmitir a la sociedad. Como hilo conductor o historia marco (historia cañamazo) el autor elige un

\footnotetext{
${ }^{5}$ Las Mil y una Noches, II, 297.

${ }^{6}$ Véase, Ángel González Palencia, Versiones castellanas del Sendebar, op.cit.
} 
argumento bien conocido desde la antigüedad y que es, ni más ni menos, que el mito de Fedra e Hipólito, adaptado a la cultura oriental:

Un rey que no tiene hijos pero que desea ardientemente un heredero, que en una coyuntura astral favorable se une a su primera esposa y concibe un hijo que goza de todos los atributos: belleza, inteligencia, bondad... pero un vaticinio le avisa de que este hijo estará en peligro durante siete días si pronuncia una sola palabra. El rey consulta al sabio preceptor Sindibād que le aconseja llevarle a un lugar de placeres donde pueda oír música y permanecer seguro hasta que pasen los 7 días. El rey manda llamar a una de sus concubinas, la más hermosa, y le pide que lo acoja en su palacio y lo cuide y proteja hasta que pasen los siete dias?.

Como "el muchacho era de una belleza y armoniosidad indescriptibles, pasó una noche en el palacio y, al verlo, el amor llamó al corazón de la favorita del rey, y no pudiendo dominarse se lanzó sobre ép'.

El muchacho le responde: "Si Dios quiere, cuando salga y vaya a ver a mi padre, lo pondré al corriente de esto y te matarä".

Entonces la concubina se presentó ante el rey y se echó sobre él llorando y sollozando. El rey le pregunta: ¿QQué tienes, cómo está tu señor? ¿¿Acaso no está bien? Ella contesta: "Mi dueño, mi señor ha querido poseerme y matarme, yo me he negado, he huido y no quiero volver ni junto a él ni al palacio". Al oír tales palabras el padre del muchacho se enfureció, convocó a sus visires y les dio la orden de que mataran a su bijo.

A partir de ahí, los visires tratan de retrasar la ejecución demostrando al rey que el muchacho es inocente y que la culpable es la favorita, contándole al rey una serie de historias en las que se muestran las maldades y los engaños de las mujeres, historias contrarrestadas por otras que cuenta la favorita para demostrar su inocencia.

Finalmente el rey se convence de la culpabilidad de la mujer y la inocencia de su hijo y cuando pasan los siete días y el príncipe puede hablar le cuenta a su padre otra historia similar y lo que había pasado en realidad entre la favorita y él:

"Juró en nombre de Dios grande y de su noble profeta que habia sido ella la que le habia tentado. El rey le creyó y añadió: "Te doy carta blanca acerca de la mujer; si quieres, manda matarla, o haz lo que quieras". Le respondió el hijo: "Expúlsala de la ciudad", y asi el hijo del rey vivió con su padre en la más cómoda de las vidas hasta que llego el destructor de las dulzuras y el separador de los amigos."

Los personajes en el Sendebar y en Las mil y una noches, aún siendo básicamente los mismos (salvo el papel fundamental del sabio preceptor), aparecen desdibujados y en algunos casos ni siquiera tienen nombre propio,

\footnotetext{
${ }^{7}$ Las Mil y una Noches, II, 297-298.

${ }^{8}$ Ibíd., II, 369.
} 
sin la fuerza ni la personalidad que tienen en la tragedia greco-latina, porque aquí lo que interesaba era poner de relieve la maldad intrínseca de las mujeres.

Los árabes no conocieron el teatro hasta fechas recientes, a partir de la nahda (renacimiento cultural árabe) y el contacto con Occidente, a finales del siglo XIX y comienzos del XX.

Las razones por las que no incorporaron el teatro a su cultura en una época como el periodo abasí en que se incorporaron otras muchas disciplinas de la cultura greco-latina, así como de la persa, india, etc. no están demasiado claras.

Hay una teoría que sostiene que al traducir en la Dār al-Hikma (Casa de la sabiduría) de Bagdad la Poética y la Retórica de Aristóteles, los traductores se confundieron o no entendieron bien los conceptos porque no tenían noción alguna de lo que era el teatro y tradujeron el término 'comedia' por $b i \hat{y} \vec{a}$ ' (sátira) y tragedia por madīh (panegírico) ${ }^{9}$ pero esta teoría parece demasiado simple y quizás haya que buscar otras razones.

Es muy posible que las razones sean más bien de índole moral y religiosa: en primer lugar, las continuas alusiones a los dioses del Olimpo iban radicalmente en contra del Islam, que erradicó por completo la idolatría y persiguió a los idólatras (asociadores, en el Corán). Por otra parte, la propia temática de la tragedia griega, con amores ilícitos, incestos y demás, atentaban de frente contra la moral islámica.

Por tanto, parece lógico que en esta sociedad donde la religión y el estado van tan unidos y es difícil separar uno de otro, se desechara por completo este género y se tradujeran solamente del griego y el latín obras científicas de materias que interesaban a la sociedad árabe medieval como las matemáticas, medicina, botánica, geografía, etc. y en el terreno de las letras se limitaron solamente a la filosofía y a la crítica literaria que interesaba enormemente a los filólogos de Kufa, Basra y Bagdad.

Sí se tradujeron, en cambio, los repertorios de cuentos y apólogos procedentes de la India que entraron en la literatura árabe a través del persa, ya que contenían mensajes didácticos y morales que interesaban para la educación de los jóvenes príncipes y nobles, y entre estas obras destacan las tres ya citadas: el Kalila y Dimna, el Sendebar y Las mil y una noches, si bien se piensa que estas obras, al pasar a la literatura árabe, fueron convenientemente islamizadas, eliminando todas las referencias a los antiguos dioses de estas culturas anteriores al Islam.

Por tanto, el mito de Fedra, es de suponer que forma parte de esa sabiduría ancestral, como la fábula y los refranes, que puede que surgiera en Grecia y de

${ }^{9}$ Véase Amjad Trabulsi, La critique poétique des arabes, jusqu'au Ve siècle de l'Hégire (XIe siècle de J.C.). Damasco, 1955, 74-75. 
ahí se extendió por Oriente y Occidente, o puede ser que surgiera en Oriente y los griegos la perfeccionaran y la transformaran en una de sus más célebres tragedias. 